\title{
SABİT PROTETİK RESTORASYONLARIN SÖKÜM NEDENLERİNİN KİŞİLERİN YAŞAM KALİTESİ ÜZERİNE ETKİSİNİN DEĞERLENDİRİLMESİ
}

\author{
ASSESSMENT OF THE EFFECTS OF THE REMOVING CAUSES FOR FIXED PARTIAL \\ DENTURES ON QUALITY OF LIFE OF INDIVIDUALS
}

\author{
Dr. Öğr. Üyesi Kübra DEĞíRMENCí ${ }^{*}$ Dr. Öğr. Üyesi Mustafa Hayati ATALA* \\ Prof.Dr.Handan ANKARALI**
}

Makale Kodu/Article code: 3894

Makale Gönderilme tarihi: 29.11 .2018

Kabul Tarihi: 16.04.2019

DOI : $10.17567 /$ ataunidfd.554341
Kübra Değirmenci: ORCID ID: 0000-0001-6429-4923

Mustafa Hayati Atala: ORCID ID: 00000311940703

Handan Ankaralı : ORCID ID: 0000-0002-3613-0523

\section{öz}

Amaç: Araştırmamızda çeşitli sebeplerle çıkarıması gereken sabit protetik restorasyonların başarısızlık nedenleri, kullanım süreleri, çıkarılma yöntemi ve son 6 ayda kişinin günlük hayatına nasıl etkilediğinin değerlendirilmesi amaçlanmıştır.

Gereç ve Yöntem: Araştırma yaşları $28-72(47,6 \pm 10,1)$ arasında değişen 144 katııımcı (86 kadın; 58 erkek) üzerinde gerçekleştirildi. Çalışmamızda $143(\% 99,3)$ tane metal destekli porselen restorasyon, 1 tane $(\% 0,7)$ tam metal restorasyon değerlendirildi. Demografik veriler, sabit protetik restorasyonun söküm nedeni, Ante kural'ına uygunluğu, söküm yöntemi, üye sayıSı, kullanım süresi, yapıldığı materyal, sökümünü isteyen bölüm ve hastaya yöneltilen Oral Sağlığın Günlük Hayata Etkisini Ölçen İndeks (OIDP) soruların cevapları araştırma formuna kaydedildi. İstatiksel değerlendirme için yüzdelikler ve FisherFreeman-Haltoon testleri kullanıldı.

Bulgular: Araştırmada toplam 144 adet sabit protetik restorasyon değerlendirildi. Söküm nedenleri değerlendirildiğinde, destek dişte ağrı $(\% 38,2)$, periodontal dokularda sorun $(\% 20,1)$ ve restorasyonun yenilenmesi $(\% 15,3)$ en çok görülen ilk üç sebep olarak belirlendi. Gruplar arasında OIDP sorularının cevapları değerlendirildiğinde iş/çalışma yaşamı ile psikolojik durum dışındaki değerlendirmeler açısından anlamlı bir farklılık bulunamadı.

Sonuç: Sabit protetik restorasyonların çıkarılma sebepleri arasında destek dişte ağrı en çok görülen sebeptir. Ante kuralını sağlayan ve sağlamayan restorasyonlar, görülen başarısızlık nedenleri açısından karşılaştırıldığında arada anlamlı bir fark belirlenememiştir. Sabit protetik restorasyonlarda başarının değerlendirilmesinde Ante kuralı ile beraber hastaya bağlı faktörler, dişin preparasyonu ve restorasyonun yenilenme sayısı gibi diğer faktörlerin de araştırılması gerekir.

Anahtar Sözcükler: Oral Sağıı̆ın Günlük Hayata Etkisini Ölçen İndeks, sabit protetik restorasyon, söküm yöntemi, Ante kuralı.

\section{ABSTRACT}

Objective: The aim of the research was to evaluate the causes of failure of fixed prosthetic restorations, lifetime, removal method and how it affects daily life in the last 6 months.

Materials and Methods: The study was performed on 144 participants (86 females; 58 males) ranging age 28 to 72 years $(47.6 \pm 10.1) .143(99.3 \%)$ metal fused to porcelain restoration and $1(0.7 \%)$ all metal restorations were evaluated. Demographic data, reason for removing fixed prosthetic restoration, meeting to Ante law, removing method, number of restoration units, restoration lifetime, restoration material, department requesting removing and the answers of Oral Impacts on Daily Performance (OIDP) questions were recorded in the research form. Percentages and Fisher-Freeman-Haltoon tests were used for statistical evaluation.

Results: A total of 144 fixed partial dentures were evaluated. When the reasons for removing were evaluated, toothache $(38.2 \%)$, periodontal problems $(20.1 \%)$ and renewing of restoration $(15.3 \%)$ were determined as the first three reasons. When the answers of OIDP questions were assesed, no significant difference was found except work / working life and psychological status.

Conclusion: Toothache is the most common reason for the removal of fixed partial dentures. Ante's law did not make a significant difference in the reasons of the failure of restorations. Other factors such as factors related to the patient, preparation of the tooth, and the number of renewing of the restorations should be searched in the evaluation of the success in fixed partial dentures.

Keywords: Oral Impacts on Daily Performance (OIDP), fixed partial denture, removing method, Ante law.

*Bolu Abant İzzet Baysal Üniversitesi, Diş Hekimliği Fakültesi, Protetik Diş Tedavisi Anabilim Dalı, Bolu.

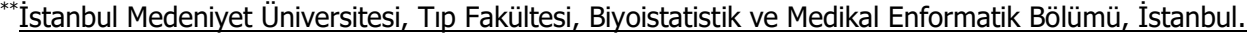

Kaynakça Bilgisi: Değirmenci K, Atala MH, Ankaralı H. Sabit Protetik Restorasyonların Söküm Nedenlerinin Kişilerin Yaşam Kalitesi Üzerine Etkisinin Değerlendirilmesi. Atatürk Üniv Diş Hek Fak Derg 2020; 30: 260-266.

Citation Information: Degirmenci $K$, Atala MH, Ankarall H. Assessment of the Effects of the Removing Causes for Fixed Partial Dentures on Quality of Life of Individuals. J Dent Fac Atatürk Uni 2020; 30: 260-266. 


\section{GİRİŞ}

Doğal dişlerin kaybedilmesi ile görülen estetik ve fonksiyonel problemlerin çözümü için sabit protetik restorasyonlar uzun bir süredir başarıyla uygulanmaktadır. Sabit protetik restorasyonların sağ kalım oranları 5 yıl için \%93.8 ve 10 yıl için \%87 olarak $^{1,2}$, 15 yıl sonrası için ise $\% 65$ olarak tahmin edilmektedir. ${ }^{3}$ Restorasyonların planlaması yapılırken diş eksikliklerinin rehabilitasyonuyla beraber çevre dokuların sağlığının korunup devam ettirilmesi de önemlidir.

1926 'da, Ante sabit protetik restorasyonların planlamasında kullanılması için bir kural tanıttı. ${ }^{4}$ Kurala göre, sabit protetik restorasyon planlaması yapılırken eksik dişlerin periodontal alanlarının dayanak olarak kullanılacak dişlerin periodontal alanlarına eşit veya daha az olmasına dikkat edilmesi başarıda etkilidir. Ante kuralı, standart sabit protez kitaplarında restorasyonların tasarımında önemli bir kural olarak öğretilmektedir. ${ }^{5,6}$ Bununla beraber, Ante kuralı kanıta dayalı değildir., ${ }^{7,8}$ İmplant tedavisinin yapılamadığı ve hastanın hareketli protez istemediği durumlarda, klinisyenler hastaların istekleri ve kalan destek dişlerin sağlığını dikkate alarak, Ante kanunu ile uyum göstermeyen uzun sabit protetik restorasyon planlanması yapabilmektedir. ${ }^{9}$ Sistematik bir derlemede, Ante kuralı referans alınarak değerlendirilen sabit protetik restorasyonların yeterli ve sağlıklı periodontal doku varlığında, karşılaştırılabilir başarı oranları elde edildiği bildirilmiştir. ${ }^{7}$ Klinik çalışmaların bulgularını tam olarak karşılaştırabilmek zordur. Çünkü, sabit protetik restorasyonların başarısında, sistemik hastalıklar ve oral hijyen gibi hastaya bağlı faktörler de etkilidir ve karşılaştırmayı zorlaştırır. ${ }^{10}$ Çalışmaların tasarım ve terminolojilerinin standardize edilerek karşılaştırmayı kolaylaştırması amacıyla Ante kuralı çalışmalarda ortak bir değişken olarak kullanılabilir. Ante kuralının sabit protetik restorasyonların prognozunda kritik olduğu belirtilmesine rağmen ${ }^{6}$, restorasyonların prognozunu nasıl etkilediğini değerlendiren çok fazla çalışma bulunmamaktadır. ${ }^{7}$

Genellikle, sabit protetik restorasyonlarla ilgili çalışmalarda protezlerin sağ kalım oranları ile görülen başarısızlık sebeplerinin değerlendirilmesi amaçlanmaktadır. Uzun dönem klinik çalışmalarda, çeşitli başarısızlıklar tanımlanmıştır. Retansiyon kaybı, porselende görülen kırıklar, restorasyonun marjinal kenar uyumunun bozulması, endodontik ve periodontal problemler sabit protetik restorasyonların çıkarılmasını gerektiren başlıca sebepler olarak bildirilmektedir.9,11 Görülen bu komplikasyonlar hastanın günlük hayatı üzerinde olumsuz etkiler gösterebilir.
Sabit protetik restorasyonlarda görülen başarısızlıklarla ilgili anket çalışmaları yapılmış olmasına rağmen ${ }^{3,12}$ bu durumun hastanın günlük yaşamını nasıl etkilediğini değerlendiren bir çalışmaya rastlanmamıştır. Klinik indeksler sınırlamalarına rağmen, kişinin sağlık profilinin mevcut durumdan nasıl etkilendiğini değerlendirmede önemli veriler sağlar. ${ }^{13} \mathrm{Bu}$ indekslerden biri olan Oral Sağlığın Günlük Hayata Etkisini Ölçen İndeks (OIDP) ağız sağlığının bireylerin günlük aktivitelerini nasıl etkilediğini değerlendirmede etkilidir. ${ }^{14}$ Uluslararası geçerliliği olan ve daha önce birçok çalışmada kullanılmış olan OIDP, yemek yeme, konuşma, dişlerin/protezlerin temizlenmesi, duygusal durum, uyuma, gülümseme, sosyal ve iş yaşamı gibi temel günlük aktiviteler ile ilgili sorular içerir. ${ }^{15,16}$ Kişinin bu sorulara verdiği cevaplar, incelenen klinik durumun, kişinin günlük yaşamını nasıl etkilediğine dair genel bir fikir sunabilir.

$\mathrm{Bu}$ bilgiler doğrultusunda çalışmamızın amacı, Ante kuralına uygun hazırlanan ve hazırlanmayan sabit protetik restorasyonların çıkarılmasını gerektiren sebeplerin, kişinin günlük hayatını nasıl etkilediğini OIDP indeksi kullanılarak karşılaştırmalı olarak değerlendirmektir.

\section{GEREÇ VE YÖNTEM}

Bu kesitsel tipteki araştırma, Bolu Abant İzzet Baysal Üniversitesi (BAİBÜ) Tıp Fakültesi Araştırma Etik Kurulu Onayı (protocol no.2017/92) ile katılımcılar yazılı ve sözlü olarak bilgilendirilerek gerçekleştirildi. Aralık 2017- Mayıs 2018 tarihleri arasında, BAİBÜ Diş hekimliği Fakültesi Protetik Diş Tedavisi Anabilim Dalı Kliniği'ne çeşitli sebeplerle sabit protetik restorasyonlarının çıkarılması için başvuran katılımcılar çalışmaya dahil edildi. Araştırmaya, okuma-yazması olmayan ve evrakları değerlendirme yetisi olmayan bireyler dahil edilmedi. Hareketli bölümlü protezleri olan bireyler, implant üstü restorasyonu olan bireyler, tek kuron restorasyonu olan bireyler, restorasyonun altında kanal tedavisi ve post olan bireyler çalışmaya dahil edilmedi. Her katılımcıya yapılacak işlem ve dolduracağı formlar ile ilgili detayı bilgiler verilerek yazılı onamı alındıktan sonra klinik değerlendirmeye geçildi.

\section{Klinik Değerlendirme}

Katılımcıların klinik ve radyografik olarak muayenesi yapıldıktan sonra, elde edilen veriler çalışma için hazırlanan forma kaydedildi. Sabit protetik restorasyonla ilgili olarak Ante kuralı́na uygunluğu, üye sayısı, kullanılma süresi, yapıldığı materyal, çıkarılmasını isteyen bölüm, çıkarılma nedeni ve çıkarılma yöntemi forma kaydedildi. 
DEĞİRMENCİ, ATALA, ANKARA

\section{İndeks Değerlendirme}

Çalışmada katılımcıların cinsiyet, yaş ve eğitim seviyesi ile ilgili demografik veriler de kaydedildi. Ayrıca, kişinin kendi ağız sağlığını değerlendirerek çok iyi, iyi, orta, kötü ve çok kötü olarak derecelendirmesi istendi. Katılımcılardan diş hekimine kontrole gitme sıklıklarını yılda en az bir kez, yılda 3-4 kez, yılda 1-2 kez veya hiç olarak tanımlamaları istendi. Diş hekimine gitme nedenleri de sorularak düzenli kontrol veya ağrı olarak kaydedildi. Formun devamında OIDP indeksi kapsamında 8 tane soru soruldu. Sorular, çıkarılması gereken sabit protetik restorasyonun yemek yeme, konuşma, diş/protez temizliği, uyku ile dinlenme, gülümseme, psikolojik durum, iş/çalışma ve sosyal yaşam gibi aktiviteleri son 6 ay içinde nasıl etkilediği ile ilgiliydi. Katılımcılar bu sekiz soruyu hiç etkilemedi, ayda 1'den az, ayda 1-2 kez, haftada 1-2 kez ve her gün olarak cevapladı. Katılımcılardan elde edilen veriler SPSS programına kaydedildi.

\section{İstatiksel Değerlendirme}

Toplam 144 formdan elde edilen verilerin istatiksel değerlendirmeleri İstanbul Medeniyet Üniversitesi Tıp Fakültesi Bioistatistik ve Medikal Enformatik Bölümü'nde gerçekleştirildi. Tüm verilerin istatistiksel analizleri Statistical Package for Social Sciences (SPSS) version 23 (SPSS Inc. Headquarters, Chicago, Illinois, ABD) paket programı kullanılarak yapıldı. Önem seviyesi olarak $p<0.05$ seçildi. Yüzdelikler ve FisherFreeman-Haltoon testleri kullanıldı.

\section{BULGULAR}

Çalışma grubunu yaşları 28-72 arasında

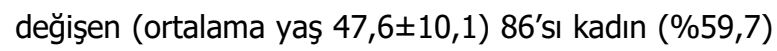
58 'i erkek $(\% 40,3)$ toplam 144 birey oluşturmaktadır. Araştırmada yer alan bireylerin \%36,1'inin ilkokul mezunu, \%36,1'inin ortaokul-lise mezunu, \%40'ının ise üniversite mezunu olduğu belirlendi. Katılımcıların aylık gelir düzeyleri değerlendirildiğinde \%13,9'nun düşük gelirli, \%79,9'nun orta gelirli ve $\% 6,3$ ün ise yüksek gelirli olduğu belirlendi (Tablo 1).

Katılımcıların \%90'ı Diş hekimine ağrı veya şikayet varlığında gittiğini belirtirken \%10 u düzenli kontrol için gittiklerini belirtti. Son 5 yıl içinde hekime gitme sıklığı değerlendirildiğinde \%45 i, 1-2 defa diş hekimine gittiğini belirtirken \%11'i yılda en az 1 kez gittiğini belirtti (Tablo 2).
Tablo 1 Katılımcıların cinsiyet, eğitim durumu ve gelir düzeylerine göre dağııımı.

\begin{tabular}{|c|c|c|c|}
\hline & & $\mathrm{N}$ & $\%$ \\
\hline \multirow{2}{*}{$\begin{array}{l}\text { Hastanın } \\
\text { cinsiyeti }\end{array}$} & Kadın & 86 & 59,7 \\
\hline & Erkek & 58 & 40,3 \\
\hline \multirow[t]{3}{*}{ Eğitim } & İlkokul mezunu & 52 & 36,1 \\
\hline & Ortaokul-lise mezunu & 52 & 36,1 \\
\hline & Üniversite mezunu & 40 & 27,8 \\
\hline \multirow[t]{3}{*}{ Gelir } & Düşük & 20 & 13,9 \\
\hline & Orta & 115 & 79,9 \\
\hline & Yüksek & 9 & 6,3 \\
\hline
\end{tabular}

Çıkarılması gereken sabit protetik restorasyonların 143 tanesi metal destekli porselen, 1 tanesi ise tam metal restorasyondur (Tablo 3). Bundan dolayı, çalışmamızda restorasyonların yapıldığı materyallerin arasında bir karşılaştırma yapılamamıştır.

Tablo 2 Katılımcıların diş hekimine gitme nedeni ve sıklığı dağılımı.

\begin{tabular}{|l|l|c|c|}
\hline \multicolumn{2}{|c|}{} & $\mathrm{n}$ & $\%$ \\
\hline \multirow{2}{*}{$\begin{array}{l}\text { Diş Hekimine Hangi nedenle } \\
\text { gidersiniz? }\end{array}$} & Düzenli kontrol & 14 & 9,7 \\
\cline { 2 - 4 } & Ağrı veya şikayet & 130 & 90,3 \\
\hline \multirow{2}{*}{$\begin{array}{l}\text { Diş hekimine son 5 yıl } \\
\text { içinde hangi sıklıkla gittiniz? }\end{array}$} & Yılda en az bir kez & 17 & 11,8 \\
\cline { 2 - 4 } & Yılda 3-4 & 40 & 27,8 \\
\cline { 2 - 4 } & Yılda 1-2 & 65 & 45,1 \\
\cline { 2 - 5 } & Hiç & 22 & 15,3 \\
\hline
\end{tabular}

Tablo 3 Restorasyonların yapıldıkları materyale göre dağıımı.

\begin{tabular}{llc|c} 
& & $\mathrm{n}$ & $\%$ \\
\hline $\begin{array}{l}\text { Sabit } \\
\text { Restorasyonun } \\
\text { yapıldığı materyal }\end{array}$ & Metal destekli porselen & 143 & 99,3 \\
\cline { 2 - 4 } & Full metal restorasyon & 1 & 0,7 \\
\hline
\end{tabular}

Sabit protetik restorasyonların ağızda kalma süreleri değerlendirildiğinde, \%6,3 ün 0-6 ay arası, $\% 4,9$ un 6 ay-1yıl arası, \%34'nün 1-5 yıl arası, $\% 22,2$ 'nin 6-10 yıl arası ve \%32,6 nın ise 10 yıldan fazla olduğu belirlendi (Tablo 4).

Sabit protetik restorasyonların kullanım sürelerinin Ante kuralına uygun yapılıp yapılmaması ile olan bağlantısı değerlendirildiğinde, anlamlı bir ilişki bulunamadı $(p=0,428)$ (Tablo 5$)$.

Sabit protetik restorasyonların çıkarılma yöntemi ile üye sayısı arasındaki ilişki değerlendirildiğinde anlamlı bir fark belirlenemedi $(p=0,120)$ (Tablo 6).

Tablo 4 Restorasyonların kullanılma sürelerine göre dağııımı.

\begin{tabular}{l|l|c|c}
\hline & & $\mathrm{n}$ & $\%$ \\
\hline Sabit Restorasyonun & $0-6$ ay arası & 9 & 6,3 \\
\cline { 2 - 4 } kullanılma süresi & 6 ay- 1 yıl & 7 & 4,9 \\
\cline { 2 - 4 } & $1-5$ yıl & 49 & 34,0 \\
\hline $6-10$ yıl & 32 & 22,2 \\
\hline & 10 yıldan fazla & 47 & 32,6 \\
\hline
\end{tabular}


Tablo 5 Sabit Protetik Restorasyonların Ante kuralına göre planlanması ile kullanım süreleri arasındaki bağlantı.

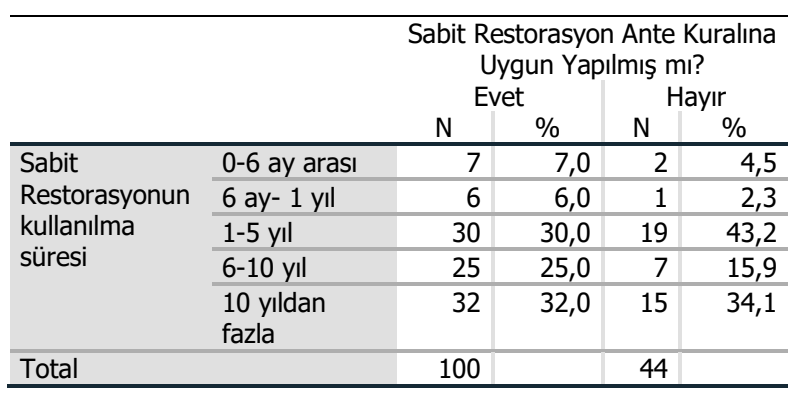

Tablo 6 Sabit protetik restorasyonların üye sayıları ile çıkarılma yöntemleri arasındaki bağlantı.

\begin{tabular}{|c|c|c|c|c|c|c|c|}
\hline & \multicolumn{6}{|c|}{ Sabit Restorasyonun üye sayısI } \\
\hline & & \multicolumn{2}{|c|}{$1-3$ arası } & \multicolumn{2}{|c|}{ 4-6 arası } & \multicolumn{2}{|c|}{7 ve daha fazla } \\
\hline & & $\mathrm{n}$ & $\%$ & $\mathrm{n}$ & $\%$ & $\mathrm{n}$ & $\%$ \\
\hline \multirow{5}{*}{\begin{tabular}{|c|} 
Sabit \\
Restorasyo \\
nun \\
çıkarılma \\
yöntemi
\end{tabular}} & $\begin{array}{c}\text { Otomatik } \\
\text { köprü sökücü }\end{array}$ & 8 & 16,7 & 7 & 16,7 & 5 & 9,3 \\
\hline & $\begin{array}{c}\text { Manuel köprü } \\
\text { sökücü }\end{array}$ & 37 & 77,1 & 28 & 66,7 & 41 & 75,9 \\
\hline & $\begin{array}{l}\text { Vestibül } \\
\text { kesilerek }\end{array}$ & 3 & 6,3 & 2 & 4,8 & 6 & 11,1 \\
\hline & \begin{tabular}{|l} 
Vestibül+ling \\
ual/palatinal \\
kesilerek
\end{tabular} & 0 & 0,0 & 5 & 11,9 & 1 & 1,9 \\
\hline & Parçalanarak & 0 & 0,0 & 0 & 0,0 & 1 & 1,9 \\
\hline & otal & 48 & & 42 & & 54 & \\
\hline
\end{tabular}

Sabit protetik restorasyonların çıkarımasını isteyen bölüm değerlendirildiğinde $\% 40,3$ ile Endodonti en yüksek oranı, $\% 1,4$ ile restoratif diş tedavisi en düşük oranı göstermiştir (Tablo 7). Sabit restorasyonun çıkarılma nedeni değerlendirildiğinde ise destek dişlerde ağrı $\% 38,2$ oranı ile en sık görülen, ekstraoral fistül, intraoral fistül ve gövde altında çekimi gereken kök bulunması $\% 0,7$ oranları ile en az görülen sebeplerdir (Tablo 8).

Katılımclların OIDP sorularına verdikleri cevap- lar ile restorasyonların Ante kuralını sağlama durumu arasındaki bağlantı değerlendirildi. Ante kuralına uymayan grupta psikolojik duruma ayda $1^{\prime}$ den az cevabını verenlerin sıklğı anlamlı düzeyde daha yüksek, her gün cevabını verenler ise Ante kuralına uyan grupta anlamlı düzeyde daha yüksek bulundu $(p=0,009)$. Psikolojik duruma verilen diğer cevaplar açısından ise gruplar arasında anlamlı fark bulunmadı (Tablo 8). Ayrıca iş/çalışma hiç etkilemedi cevabını verenler Ante kuralına uyanlarda, ayda $1^{\prime}$ den az etkiledi cevabını verenler ise Ante kuralına uymayanlarda anlamlı düzeyde daha yüksek bulundu $(p=0,027)$. Bu problemlerin dışında kalan problemler açısından Ante kuralına uyan ve uymayanlar arasında anlamlı farka rastlanmadı.
Tablo 7. Sabit protetik restorasyonların çıkarılmasını isteyen bölümlere göre dağılımı.

\begin{tabular}{ll|c|c} 
& & $\mathrm{n}$ & $\%$ \\
\hline $\begin{array}{l}\text { Sabit Restorasyonun } \\
\text { çıarııımasını isteyen } \\
\text { bölüm }\end{array}$ & Oral Diagnoz & 6 & 4,2 \\
\cline { 2 - 4 } & Periodontoloji & 27 & 18,8 \\
\cline { 2 - 4 } & Ağız,Diş ve Çene cerrahisi & 19 & 13,2 \\
\cline { 2 - 4 } & Protetik diş tedavisi & 32 & 22,2 \\
\cline { 2 - 4 } & Endodonti & $\mathbf{5 8}$ & $\mathbf{4 0 , 3}$ \\
\cline { 2 - 4 } & Restoratif Diş Tedavisi & 2 & 1,4 \\
\hline
\end{tabular}

Tablo 8. Sabit protetik restorasyonların çıkarılma nedenlerine göre dağılımı.

\begin{tabular}{|c|c|c|c|}
\hline & & $\mathrm{n}$ & $\%$ \\
\hline \multirow{12}{*}{$\begin{array}{l}\text { Sabit } \\
\text { Restorasyonun } \\
\text { Çıkarılma } \\
\text { Nedeni }\end{array}$} & Desimantasyon & 5 & 3,5 \\
\hline & Destek dişlerde ağrı & 55 & 38,2 \\
\hline & ekstraoral fistül & 1 & 0,7 \\
\hline & intraoral fistül & 1 & 0,7 \\
\hline & periodontal dokularda sorun & 29 & 20,1 \\
\hline & diş çekimi & 15 & 10,4 \\
\hline & sabit restorasyonlarda kırık olması & 3 & 2,1 \\
\hline & hastanın estetik şikayeti & 3 & 2,1 \\
\hline & restorasyonun yenilenmesi & 22 & 15,3 \\
\hline & destek dişlerde çürük olması & 7 & 4,9 \\
\hline & $\begin{array}{l}\text { restorasyonun olduğu bölgede } \\
\text { kist/tümör bulunması }\end{array}$ & 2 & 1,4 \\
\hline & $\begin{array}{l}\text { gövde altında çekimi gereken kök } \\
\text { bulunması }\end{array}$ & 1 & 0,7 \\
\hline
\end{tabular}

Tablo 9 Katılımcıların OIDP sorularına verdikleri cevaplar ile Ante kanuna uygun yapılan restorasyonlar arasındaki ilişki.

\begin{tabular}{|c|c|c|c|c|c|c|}
\hline & & \multicolumn{4}{|c|}{$\begin{array}{c}\text { Sabit Restorasyon Ante Kuralına } \\
\text { Uygun Yapılmış mı? }\end{array}$} & \multirow[b]{3}{*}{$\mathrm{p}$} \\
\hline & & \multicolumn{2}{|c|}{ Evet $(N=100)$} & \multicolumn{2}{|c|}{ Hayır $(\mathrm{N}=44)$} & \\
\hline & & $\mathrm{N}$ & $\%$ & $\mathrm{n}$ & $\%$ & \\
\hline \multirow{5}{*}{ Yemek yeme } & hiç etkilemedi & 50 & 50,0 & 21 & 47,7 & \multirow[t]{5}{*}{0,457} \\
\hline & ayda 1 'den az & 10 & 10,0 & 2 & 4,5 & \\
\hline & ayda 1-2 kez & 13 & 13,0 & 10 & 22,7 & \\
\hline & haftada $1-2 \mathrm{kez}$ & 6 & 6,0 & 4 & 9,1 & \\
\hline & her gün & 21 & 21,0 & 7 & 15,9 & \\
\hline \multirow[t]{5}{*}{ Konuşma } & hiç etkilemedi & 66 & 66,0 & 30 & 68,2 & \multirow[t]{5}{*}{0,479} \\
\hline & ayda 1 'den az & 9 & 9,0 & 2 & 4,5 & \\
\hline & ayda 1-2 kez & 9 & 9,0 & 7 & 15,9 & \\
\hline & haftada $1-2 \mathrm{kez}$ & 5 & 5,0 & 3 & 6,8 & \\
\hline & her gün & 11 & 11,0 & 2 & 4,5 & \\
\hline \multirow{5}{*}{$\begin{array}{l}\text { Diş/Protez } \\
\text { Temizleme }\end{array}$} & hiç etkilemedi & 60 & 60,0 & 27 & 61,4 & \multirow[t]{5}{*}{0,930} \\
\hline & ayda 1 'den az & 12 & 12,0 & 7 & 15,9 & \\
\hline & ayda $1-2 \mathrm{kez}$ & 9 & 9,0 & 3 & 6,8 & \\
\hline & haftada $1-2$ kez & 8 & 8,0 & 2 & 4,5 & \\
\hline & her gün & 11 & 11,0 & 5 & 11,4 & \\
\hline \multirow{5}{*}{$\begin{array}{l}\text { Uyku ve } \\
\text { Dinlenme }\end{array}$} & hiç etkilemedi & 72 & 72,0 & 29 & 65,9 & \multirow[t]{5}{*}{0,271} \\
\hline & ayda 1 'den az & 8 & 8,0 & 4 & 9,1 & \\
\hline & ayda 1-2 kez & 5 & 5,0 & 5 & 11,4 & \\
\hline & haftada $1-2$ kez & 2 & 2,0 & 3 & 6,8 & \\
\hline & her gün & 13 & 13,0 & 3 & 6,8 & \\
\hline \multirow[t]{5}{*}{ Gülümseme } & hiç etkilemedi & 65 & 65,0 & 31 & 70,5 & \multirow[t]{5}{*}{0,391} \\
\hline & ayda 1 'den az & 7 & 7,0 & 6 & 13,6 & \\
\hline & ayda $1-2 \mathrm{kez}$ & 8 & 8,0 & 1 & 2,3 & \\
\hline & haftada $1-2 \mathrm{kez}$ & 4 & 4,0 & 2 & 4,5 & \\
\hline & her gün & 16 & 16,0 & 4 & 9,1 & \\
\hline \multirow{5}{*}{$\begin{array}{l}\text { Psikolojik } \\
\text { Durum }\end{array}$} & hiç etkilemedi & 60 & 60,0 & 27 & 61,4 & \multirow[t]{5}{*}{0,009} \\
\hline & ayda 1 'den az & 7 & 7,0 & 8 & 18,2 & \\
\hline & ayda $1-2 \mathrm{kez}$ & 4 & 4,0 & 0 & 0,0 & \\
\hline & haftada $1-2 \mathrm{kez}$ & 5 & 5,0 & 6 & 13,6 & \\
\hline & her gün & 24 & 24,0 & 3 & 6,8 & \\
\hline \multirow[t]{5}{*}{ İş/Çalışma } & hiç etkilemedi & 79 & 79,0 & 30 & 68,2 & \multirow[t]{5}{*}{0,027} \\
\hline & ayda 1 'den az & 8 & 8,0 & 8 & 18,2 & \\
\hline & ayda $1-2 \mathrm{kez}$ & 3 & 3,0 & 1 & 2,3 & \\
\hline & haftada $1-2 \mathrm{kez}$ & 1 & 1,0 & 4 & 9,1 & \\
\hline & her gün & 9 & 9,0 & 1 & 2,3 & \\
\hline \multirow[t]{5}{*}{ Sosyal Yaşam } & hiç etkilemedi & 70 & 70,0 & 30 & 68,2 & \multirow[t]{5}{*}{0,418} \\
\hline & ayda 1 'den az & 7 & 7,0 & 5 & 11,4 & \\
\hline & ayda $1-2 \mathrm{kez}$ & 7 & 7,0 & 3 & 6,8 & \\
\hline & haftada $1-2 \mathrm{kez}$ & 4 & 4,0 & 4 & 9,1 & \\
\hline & her gün & 12 & 12,0 & 2 & 4,5 & \\
\hline
\end{tabular}




\section{TARTIŞMA}

Günümüzde metal destekli restorasyonlar başarılı uzun dönem sonuçları ile sık tercih edildiğinden 'altın standart' olarak belirtilmiştir. ${ }^{17}$ Ülkemizdeki devlet hastanelerinde, sıklıkla planlanan metal destekli porselen restorasyonların yenilenme hakları hastalara 4 yılda bir verilmektedir. Hastaların restorasyonlarını bu süre boyunca sorunsuz kullanabilmesi için ağız sağığına dikkat etmesi ve diş hekimine düzenli kontrollerine gitmesi gerekmektedir. Bununla beraber, erişkin ve yaşlı hastalarda ağız diş sağığı profilinin değerlendirildiği bir çalışmada ${ }^{18}$, erişkin ve yaşlı hastaların \%88,2 ve \%98,4 oranlarında yakınmaları olduğunda diş hekimine gittikleri sonucuna varılmıştır. Bu çalışmayla uyumlu olarak araştırmamızda katılımcıların \%90'nın bir şikayet veya ağrı durumunda diş hekimine gittikleri sadece $\% 10^{\prime}$ un düzenli kontrollerine dikkat ettikleri belirlenmiştir. Bu sonucu etkileyen en önemli parametrenin hastanın sosyoekonomik durumu olabileceği düşünüldü. Diğer bir deyişle, hastalar sosyoekonomik durumlarını göz önünde bulundurarak, rahatsız oldukları protezlere sabır göstermişlerdir.

Sabit protetik restorasyonun uzun ömürlü olmasında hekimin yaptığı planlama da önemlidir. Ante kuralı, restorasyon planlaması yapılırken hekimlerin genel olarak dikkate aldığı temel bir kuraldır. Bununla beraber, literatüre bakıldığında Ante kuralınının restorasyonların değiştirilme sebeplerini ve hastanın yaşamına olan etkilerini değerlendiren bir klinik çalışmaya rastlanmamıştır. Bundan dolayı, çalışmamızda sabit protetik restorasyonların değiştirilmesini gerektiren faktörlerin kişinin günlük yaşamını nasıl etkilediği Ante kanunu referans alınarak değerlendirilmiştir. Çalışmamızda, sabit protetik restorasyonların kullanım süreleri ile Ante kanununa uyum göstermesi arasında anlamlı bir ilişki belirlenemedi. Direk bir bağlantı bulunamamasının nedeni olarak hastaya bağı faktörlerin de etkili olmasından kaynaklanmaktadır. Kişilerin ağız hijyeni, periodontal dokuların durumu sabit protetik restorasyonların ömrünü etkiler. Sabit protetik restorasyonların planlanması yapılırken periodontal dokuların devamlıı̆̆ı dikkate alınır. Ancak, diş hareketliliğinin kendi başına patolojik bir durum göstermediği değişen fonksiyona fizyolojik adaptasyon olarak tanımlanabileceği belirtilmektedir. ${ }^{19} \mathrm{Bu}$ nedenle, Ante kanununa uyum göstermeyen periodontal yapı varlığında da sabit protetik restorasyonlar planlanabilir. ${ }^{7}$ Benzer şekilde, periodontal hastalık geçmişi olan hastalara yapılan sabit protetik restorasyonlar dikkatli planlandığında ve düzenli kontroller yapıldığında herhangi bir periodontal problem görülmeden kullanılabildiği belirtilmiştir. ${ }^{20}$ Protetik restorasyonlarda kuvvet iletimini değerlendiren çalışmalarda, azalmış periodontal desteği olan dişlerin desteklik sağlayabilmesi için, çiğneme paternini olumsuz etkilemeyecek şekilde kuvvet dağılımının sağlanması gerektiği ifade edilmiştir. ${ }^{21} \mathrm{Bu}$ sebeplerden dolayı, Ante kuralı'nın restorasyonların ömrünü nasıl etkileyebileceğine dair kesin sonuçlar sunabilmek zordur.

Çalışmamızda çıkarılması gereken restorasyonların sebepleri değerlendirildiğinde gruplar arasında anlamlı bir farklılık belirlenmemiştir. Destek dişlerde ağrı \%38,2 oranı ile en çok görülen sebep olarak belirlenirken, \%20,1 oranı ile periodontal sorun ve $\% 15,3$ oran ile restorasyonun yenilenmesi takip eden sebeplerdir. Çalışmamızın sonucu, Özdemir ve ark.'nın çalışmasında belirlenen \%37,4 ile destek dişte ağrı, $\% 20$ periodontal sorun ve \%15,6 ile yenileme sabit protetik restorasyonların söküm nedenleri ile benzerlik göstermektedir. ${ }^{22}$ Prepare edilen vital dişlerin herhangi bir belirti göstermeden restorasyonlara desteklik sağlama oranı $5,10,20$ ve 25 yıl sonrasında sırasıyla $\% 98, \% 92, \% 87$ ve $\% 83$ olarak tahmin edilmektedir. ${ }^{23}$ Prepare edilen dişlerin simantasyonu takiben $10 \mathrm{yll}$ içerisinde \%13,3 oranında kanal tedavisi gerektirdiği bildirilmektedir. ${ }^{24}$ Cheung ve arkadaşları, metal destekli seramik restorasyonların söküm nedenlerini değerlendirdiklerinde, destek dişte endodontik tedavi intiyacının en sık görülen sebep olduğunu belirlemişlerdir. ${ }^{25}$ Çalışmamızın bulguları bu araştırmalar ile uyum göstermektedir. Değerlendir- diğimiz restorasyonların \%54,86 sının 6 yıldan uzun süredir kullanıldığı ve restorasyonların çıkarılma sebep- leri arasında destek dişteki ağrı şikayetinin ilk sırayı aldığı belirlenmiştir.

Sabit protetik restorasyonların çıkarılmasında kullanılan birçok yöntem tanımlanmıştır. ${ }^{26}$ Restorasyonların çıkarılması sırasında, diş ve çevre dokulara zarar vermeden kontrollü kuvvetlerin yavaş yavaş arttırılarak uygulanması, herhangi bir direnç ile karşılaşıldığında ise işlemin durdurulması gerektiği bildirilmiştir. Klinikte pratik olması nedeniyle daha çok manuel veya otomatik kuron-köprü sökücüler ile vurarak çıkarma, restorasyonun vestibül veya lingual yüzünden kesim yaparak restorasyonu çıkarma yöntemleri kullanılmaktadır. Sabit protetik restorasyonların sökümü sırasında uygulanan kuvvetin çevre dokulara ve destek dişlere zarar vermemesine dikkat edilmesi önemlidir. ${ }^{27}$ Bundan dolayı,çalışmamızda küçük kuvvetler uygulanarak işleme başlanmış ve daha sonra 
kuvvet yavaş yavaş arttırılmıştır. Manuel ve otomatik köprü sökücüler ile çıkarılamayan restorasyonlar kesilerek çıkarılmıştır. Çalışmamızda, sabit protetik restorasyonların çıkarılmasında en çok kullanılan yöntem manuel köprü sökücü kullanımı olarak belirlendi. Bu çalışmada, kullanılan çıkarma yöntemi ile sabit protetik restorasyonun üye sayısı değerlendirildiğinde anlamlı bir ilişki belirlenemedi. Özdemir ve ark.'ının çalışmasında üye sayısı 7 ve daha fazla olan restorasyonların, çıkarılma işlemi sırasında vestibül ve lingual yüzlerde kesim gerektirmesi daha yüksek oranda görülmüştür. ${ }^{22}$ Çalışmamızda restorasyonların sadece \%12,5'inin kesilerek çıkarılmasının, destek dişlerin preperasyonlarının giriş yolunu destekler nitelikte olmasından kaynaklandığını düşündürmektedir.

Sabit protetik restorasyonların estetik ve fonksiyonel devamlılığını etkileyen nedenler restorasyonların çıkarılmasını gerektirir ve kişinin günlük aktivitelerini de etkileyerek rahatsız eder. ${ }^{3}$ Bu sebeplerin günlük aktiviteleri nasıl etkilediği daha önce değerlendirilmemiştir.

Bu çalışmada Ante kanunu sağlayan ve sağlamayan sabit protetik restorasyonların çıkarılması zorunlu hale geldiğinde hastanın günlük yaşamını nasıl etkilediği OIDP anketi ile değerlendirilmiştir. Yapılan bir çalışmada hastaların protetik ve konservatif tedavi ihtiyaçlarının elde edilen OIDP skorları ile birbirini desteklediği belirlenmiştir. ${ }^{28}$

Çalışmamızda OIDP skorları ile çıkarılması gereken sabit protetik restorasyonların hastanın günlük yaşamını nasıl etkilediği değerlendirildiğinde ise, kişinin psikolojik durumunun Ante kanunu sağlayan grupta daha sık etkilemiş olduğu görüldü. İş/çalışma hayatına olan etki değerlendirildiğinde ise Ante kanununa uyan grupta hiç etkilemedi cevabı daha yüksek oranda belirlendi. OIDP indeksinin değerlendirdiği diğer günlük aktiviteler açısından gruplar arasında anlamlı bir farkIılık görülmedi. Bu sonuca göre söz konusu problemlerin yaşanma sıklığının Ante kuralı ile ilişkili olmadığı söylenebilir. Kişilerin sosyal ve iş yaşamlarındaki farkIılıklar ile mevcut duruma sabır göstermeleri de farklılık gösterebilmektedir. Bundan dolayı, restorasyonun Ante kuralı ile hastanın günlük yaşamını değerlendirmesi arasında bir bağlantı kurulamadığı düşünülmektedir.

Çalışmamızda başarısız olan sabit protetik restorasyonlar değerlendirilmiştir. Başarısızlığa neden olan bir çok faktör söz konusudur. Bununla beraber, Ante kuralı başarıyı sağlayan kesin bir kriter olarak belirlenememiştir. Başarıda etkili olabilecek, destek dişlerin preparasyonu, restorasyonların kaçıncı defa yenilendiği ve hastaların hijyen alışkanlıkları çalışmamızda değerlendirilmemiştir. Ante kuralının daha net değerlendirilebilmesi için sabit protetik restorasyonlarda etkili olan daha çok faktörün değerlendirildiği çalışmaların yapılıması faydalı olacaktır.

\section{SONUÇ}

Çalışmamızın sınırları dahilinde Ante kanunu ile sabit protetik restorasyonların başarısı arasında direk bir bağlantı belirlenememiştir. Sabit protetik restorasyonların prognozu birçok faktörden etkilenebilmektedir. Hastaların düzenli kontrole gelmemeleri sabit protetik restorasyonların en çok çıkarılma sebebinin destek dişte ağrı olmasına neden olabilmektedir. Sabit protetik restorasyonların yapımında hastaların bilgilendirilmesi ve hekime düzenli gelmeleri sağlanarak başarıyı etkileyen faktörler değerlendirilebilir.

NOT: Çalışmada herhangi bir yazar, kurum ya da kuruluş ile çıkar çatışması içerisinde bulunmamaktadır. Makale daha önce hiçbir yerde yayınlanmamış ve yayınlanmak üzere işlem görmemektedir

\section{KAYNAKLAR}

1. Pjetursson BE, Brägger U, Lang NP, Zwahlen M. Comparison of survival and complication rates of tooth-supported fixed dental prostheses (FDPs) and implant-supported FDPs and single crowns (SCs). Clin Oral Implants Res 2007;18:97-113.

2. Nicolaisen $M H$, Bahrami G, Schropp L, Isidor F. Comparison of metal-ceramic and all-ceramic three-unit posterior fixed dental prostheses: a 3year randomized clinical trial. Int J Prosthodont 2016;29:259-64.

3. De Backer $\mathrm{H}$, Van Maele G, De Moor N, Van den Berghe L, De Boever J. A 20-year retrospective survival study of fixed partial dentures. Int ] Prosthodont 2006;19:143-53.

4. Ante I. The fundamental principles of abutment. Michigan D Soc Bull. 1926;8:14-23.

5. Rosentiel SF FJ. Contemporary Fixed Prosthodontics. 4th ed. St Louis: Mosby Elsevier; 2006. p.95.

6. Shillingburg HT. Fundamentals of Fixed Prosthodontics. 3rd ed. Chicago: Quintessence; 1997.p.75.

7. Lulic M, Bragger U, Lang NP, Zwahlen M, Salvi GE. Ante's (1926) law revisited: a systematic review on survival rates and complications of fixed dental prostheses (FDPs) on severely reduced periodontal 
DEĞİRMENCI, ATALA, ANKARA

tissue support. Clin Oral Implants Res 2007;18:6372.

8. Chitumalla $R$, Munaga $S$, Khare A, Agarwal $S$, Bhoyar A, Parlani S. Stress distribution among periodontally compromised abutments: a comparative study using three-dimensional finite element analysis. Contemp Clin Dent 2012;3:4528.

9. Rehmann P, Podhorsky A, Schaaf D, Rudel K, Wostmann B. Long-span fixed dental prostheses not meeting Ante's law: a retrospective analysis. Quintessence Int 2015;46:51-7.

10. Tan K, Pjetursson BE, Lang NP, Chan ES. A systematic review of the survival and complication rates of fixed partial dentures (FPDs) after an observation period of at least 5 years. Clin Oral Implants Res 2004;15:654-66.

11. Al Moaleem MM. Systems and techniques for removal of failed fixed partial dentures: a review. Am J Health Res 2016;4:109-16.

12. Eliasson A, Arnelund CF, Johansson A. A clinical evaluation of cobalt-chromium metal-ceramic fixed partial dentures and crowns: a three-to seven-year retrospective study. J Prosthet Dent 2007;98:6-16.

13. John MT, Reissmann DR, Čelebić A, Baba K, Kende $D$, Larsson $P$, Rener-Sitar K. Integration of oral health-related quality of life instruments. J Dent 2016;53:38-43.

14. Peker I, Alkurt MT. Oral impacts on daily performance in Turkish adults attending a dental school. J Contemp Dent Pract 2014;15:92-8.

15. Dorri M, Sheiham A, Tsakos G. Validation of a Persian version of the OIDP index. BMC Oral Health 2007;7:2-9.

16. Maia FB, de Sousa ET, de Sousa JP, Scudine KG, Freitas CM, Sampaio FC,Forte FD. Influence of the dental prosthetic status on self-perceptions of health and treatment needs: a cross-sectional study of middle-aged adults with chronic disease. J Clinical Exp Dent 2018;10:567-73.

17. Ertürk BK, Çömlekoğlu MD, Çömlekoğlu E, Güngör MA. Sabit protetik restorasyonlarda kullanilan güncel tasarim ve üretim yöntemleri. Atatürk Üniv Diş Hek Fak Derg 2015;25:135-43.

18. Gökalp S, Güçiz Doğan B, Tekçiçek $M$, Berberoğlu A, Ünlüer Ş. Erişkin ve yaşlılarda ağız-diş sağlığı profili, Türkiye-2004. Hacettepe Diş Hek Fak Derg 2007;31:11-8.

19. Akça K, Uysal S, Çehreli MC. Implanttooth-supported fixed partial prostheses: correlations between in vivo occlusal bite forces and marginal bone reactions. Clin Oral Implants Res 2006;17:331-6.

20. Kinumatsu T, Umehara K, Nagano K, Saito A. Periodontal therapy for severe chronic periodontitis with periodontal regeneration and different types of prosthesis. Bull Tokyo Dent Coll 2014;55:21724.

21. Peck CC. Biomechanics of occlusion-implications for oral rehabilitation. J Oral Rehabil 2016;43:20514.

22. Özdemir N, Coşkun Akar G, Uluer H, Aksoy G. Sabit protetik restorasyonların söküm nedenleri ve yöntemlerinin değerlendirilmesi. Ege Üniv Diş Hek Fak Derg 2007;28:169-77.

23. Valderhaug J, Jokstad A, Ambjørnsen E, Norheim P. Assessment of the periapical and clinical status of crowned teeth over 25 years. J Dent 1997;25:97-105.

24. Whitworth J, Walls A, Wassell R. Crowns and extra-coronal restorations: endodontic considerations: the pulp, the root-treated tooth and the crown. Br Dent J 2002;192:315-20.

25. Cheung GS, Lai SC, Ng RP. Fate of vital pulps beneath a metal-ceramic crown or a bridge retainer. Int Endod J 2005;38:521-30.

26. Sağsöz N, Yanıkoğlu N, Aladağ L, Özdemir H, Çiftçi H. Sabit protetik restorasyonların söküm nedenlerinin araştırılması ve geleneksel söküm yöntemleri ile kavo coronaflex restorasyon sökücüsünün karşılaştırılması. Atatürk Üniv Diş Hek Fak Derg 2014;24:378-85.

27. Verrett RG, Mansueto MA. Removal of a metal-ceramic fixed partial denture with a loose retainer. J Prosthodont 2003;12:13-6.

28. Erić J, Stančić I, Šojić LT, Popovac AJ, Tsakos G. Validity and reliability of the Oral Impacts on Daily Performance (OIDP) scale in the elderly population of Bosnia and Herzegovina. Gerodontology 2012;29:902-8.

\author{
Yazışma Adresi \\ Dr.Kübra DEĞİRMENCI \\ Bolu Abant İzzet Baysal Üniversitesi \\ Protetik Diş Tedavisi Anabilim Dalı, \\ Gölköy Kampüsü,Bolu \\ E-mail: dtkubradegirmenci@outlook.com
}

